\title{
Procedure Dosing Frequency per Interval
}

National Cancer Institute

\section{Source}

National Cancer Institute. Procedure Dosing Frequency per Interval. NCI Thesaurus.

Code C117522.

The number of doses administered for the procedure per a specific interval. 